\title{
RELATIVE EFFICACY OF DIFFERENT CONCENTRATIONS OF MINT (MENTHA LONGIFOLIA) AGAINST TRIBOLIUM CONFUSUM (COLEOPTERA: TENEBRIONIDAE)
}

\author{
Saba Memon ${ }^{1}$, Jam Ghulam Mustafa Sahto ${ }^{2 *}$, Lubna Bashir ${ }^{1}$, Imtiaz Ahmed Nizamani ${ }^{3}$ and Abdul \\ Qayoom Rajput ${ }^{2}$ \\ ${ }^{1}$ Department of Entomology Sindh Agriculture University Tando jam Sindh. \\ ${ }^{2}$ Department of Agriculture and Agribusiness Management University of Karachi \\ ${ }^{3}$ Department of Plant Protection Sindh Agriculture University Tando jam. \\ *Corresponding Authors: drgmustafajam@yahoo.com

\section{Article Received 15-06-2020, Revised 21-07-2020, Accepted 7-08-2020}

\begin{abstract}
Present study aimed to examine the effect of different concentrations of mint, Mentha longifolia (2.00 $\%, 1.50 \%, 1.00 \%$, and $0.50 \%$ ) on Tribolium confusum in wheat under laboratory conditions. All the concentrations of mint exhibited the potential to cause mortality of $T$. confusum and their effectiveness against $T$. confusum increased with time. Although, no significant difference was recorded among various mint materials to elicit mortality of $T$. confusum after 24 hours of application. However, a rise in mortality was recorded after 48 hours of application with the highest mortality of $T$. confusum also recorded in $2.00 \%$ concentration followed by $1.5 \%, 1 \%$, and $0.5 \%$ concentrations. The mortality of beetles showed further rise afterward and at the end of the week of the mortality experiment, $2.00 \%$ mint concentration cause maximum mortality. No mortality of beetles was recorded in the control. Population fluctuation results showed a significant difference in population growth at monthly intervals as a steady growth was observed in the $2 \%, 1.5 \% 1 \%$, and $0.5 \%$ concentration, but, rapid growth was recorded in the control. At the end of the third month, the highest population of $T$. confusum was recorded in control $(88.00 \pm 3.79$ beetles), whereas, the beetle population observed in $0.50 \%, 1.00 \%, 1.50 \%$, and $2 \%$ concentrations were (71.33 \pm 1.45 beetles), ( $63.00 \pm 3.46$ beetles), (53.67 \pm 2.91 beetles) and (30.00 \pm 3.61 beetles) respectively. The overall weight and grain loss were significantly higher in control, whereas, $2 \%$ of mint concentration suffered the lowest loss. Therefore, $2 \%$ of mint concentration is recommended to be used to manage the population of $T$. confusum in wheat.
\end{abstract}

Keywords: Botanical, Confused flour beetle, Mint, Population, wheat.

\section{Introduction}

Wheat (Triticum aestivum L.) is one of the vital cereal crops in the world. Wheat production is an important worldwide target to fill the gap among the growing population of not only in Pakistan but also throughout the country. Therefore, latest and innovative research has been focused during the recent years to improve the yield of wheat to decrease the gap among the world production and food requirements of the global population (Mackowaik et al., 2001; Atiyah et al., 2002; Rehmat et al., 2010). During, 2016-17, wheat was cultivated on an area of 9,052 thousand hectares in Pakistan observing a decline of 1.9 percent related to 9,224 thousand hectares cultivated during the same period last year (GoP, 2018). Food production and its safe storage are some of the major concerns faced by the world in recent years (Haq et al., 2005). It has been estimated that around 9\% of the global production of food grains is lost due to the attack of stored grain insect pests and mites, whereas, only larvae of Triobolium sp. can reduce the weight of individual grains up to $14.6 \%$ (Tooba et al., 2005). Moreover, favorable climate and poor storage facilities aggravated the situation and increase the losses (Rahman et al., 2009, Degri and zainab 2013). Generally, the major insect pests of stored wheat are lesser borer (Ryzopertha dominica), red flour beetle (Tribolium castaneum Herbst, 1797), confused red flour beetle (Tribolium confusum Herbst, 1797), maize weevil (Sitophilus zeamais Motschulsk, 1855), larger grain borer (Prostephanus triuncates Horn, 1878), granary 
weevil (Sitophilus granarium Limmaeus, 1758), rice weevil (Sitophilus oryzae Linnaeus, 1763) and Angoumois grain moth (Sitotroga cerelella Olivier, 1789). These pests cause severe problems in store grain houses, particularly in the under developing countries due to poor sanitation and the use of improper storage facilities all support the attack of pests (Lee et al., 2002). The confused flour beetle, Tribolium confusum (Coleoptera: Tenebriondiae), is a common pest insect known for attacking and infesting stored flour and grain. Adults of this beetle are easily confused with other Tribolium species. (Papachristos and Stamopoulos, 2002). Tribolium confusum is a world-wide pest, especially in cooler regions. Tribolium confusum damages a variety of stored products including dried foods, grain products and fruits, chocolate, pet foods, and dried flowers (Athanassiou et al., 2016). Economic losses consist of reduced weight and quality, difficulties in baking, reduced marketability of infested products, and an accompanying unpleasant smell. Besides, $T$. confusum is an allergen that may cause allergies in bakers (Alanko et al., 2000). It has been observed that it mostly attacks on damaged grains that intact ones (Trematerra et al., 2000). Use of synthetic chemicals poses great threats to humans, causes damage to the ozone, increases environmental pollution, and toxic to non-target organisms along with creating resistance among stored pests (Isman, 2006). Thus, such huge concerns to humans and their environment necessitate to look for the ecofriendlier and target specific control measures (Shaaya et al., 1997; Isman, 2000). Accordingly, plants and their derivatives could have gained the huge potential in the management of not only field crops but also many noxious stored pests as many of them are selective with little or no harmful influence on non-target organisms and the environment (Shaaya et al., 1997; Rajendran and Sriranjini, 2008). Among various plants evaluated for their toxicity against stored grain pests, about 25 to 30 species of genus Mentha (family Lamiaceae or Labiatae), widely located in diverse ecological zones of the world, hold prominent importance (Lange and Croteau, 1999). Wild mint, Mentha longifolia (L.), is a perennial herb that has shown very important and diversified biological and pesticidal activities against many harmful crop pests (Hajlaoui et al., 2008). Such toxicity of mint may be because of the presence of a lot of monoterpenoids such as piperitone, piperitone oxide, pulegone, piperitenone, d-limonene, menthone, carvone, caryophyllene, 1,8-Cineole and menthol (Oyedeji and Afolayan, 2006). As mint has not been exploited much against the stored grain pests in general and $T$. confusum in particular, therefore, this study was done to determines the effect of various mint concentrations on its mortality and population development.

\section{Materials and Methods}

Insect collection and rearing: The culture of $T$. confusum was obtained from the Stored Grain Research Laboratory, Department of Entomology, Sindh Agriculture University, Tandojam. Tribolium castaneum population was further reared on the pure wheat flour under controlled temperature $\left(28 \pm 2{ }^{\circ} \mathrm{C}\right)$ and $75 \pm 5 \%$ R.H in the laboratory.

Selection of plant materials and extract preparation: The leaves of Mint Mentha Longifolia was collected from the surroundings of the Sindh Agriculture University, Tandojam. The collected leaves were washed thoroughly and airdried under shade. The dried plant materials were then ground using an electric blender (GEEPAS China GCG289) and the obtained powder was sieved using a muslin cloth. Four different concentrations of mint powder i.e., $2 \%, 1.5 \%, 1 \%$, and $0.5 \%$ along with control (without mint powder) were used in the experiment. In the mortality determination bioassay, each concentration was applied in 20 grams of wheat, whereas, the same concentrations were applied in 200 gm of wheat for the population fluctuation experiment. After mixing, the powder was shacked thoroughly in seeds for about 3 minutes to create a homogenous mixture. In each container for the mortality experiment, ten beetles, whereas, twenty freshly emerged beetles of $T$. confusum were transferred for population fluctuation experiment. Each jar was tightened with an elastic rubber band to restrict beetles inside.

Determination of pest damage parameters: The efficacy of the plant materials to cause mortality was recorded after 24 hours, 48 hours, and 7 days. Population fluctuation of $T$. castaneum was 
observed at monthly intervals for three consecutive months. At the end of the experiment, weight loss was recorded by using the formula below:

Total weight loss $\%=($ Original weight - Observed weight)/Original Weight*100

Grain weight loss $\%=($ Original grain weight Observed grain weight)/Original grain weight*100 The collected data were analyzed using ANOVA and means with a significant difference were separated by the Least Square Difference test at the 0.05 probability level. All the analysis was done using STATISTIX 8.1 software.

\section{Results}

Effect of different concentrations of mint on mortality of $T$. confusum at different intervals: The mortality rate of $T$. confusum in wheat due to the application of different concentrations of mint i.e., $2.00 \%, 1.50 \%, 1.00 \%$, and $0.50 \%$ at various time intervals ( 24 hours, 48 hours and 1 week) after their application is given in Table 1. Although, all mint concentrations caused mortality immediately after their application the non-significant difference $(\mathrm{F}=3.22, \mathrm{P}<0.0607)$ was recorded among various mint materials to elicit mortality of
T. confusum after 24 hours of application. After 24 hours, the highest mortality was recorded in $2.00 \%$ mint concentration $(2.00 \pm 0.58$ beetles $)$ and followed by $1.50 \%$ concentration $(1.67 \pm 0.67$ beetles), whereas, no mortality was recorded in control. A rise in mortality was recorded after 48 hours of application as significantly $(\mathrm{F}=16.2, \mathrm{P}=$ 0.0002 ) the highest mortality of $T$. confusum was observed in $2 \%$ concentration ( $74.67 \pm 0.6$ beetles), followed by $1.5 \%$ ( $4.00 \pm 0.58$ beetles), $1 \%$ (1.67 \pm 033 beetles) and $0.5 \%(1.00 \pm 0.58$ beetles $)$ concentrations. A similar trend in the effectiveness of various mint concentrations regarding their effectiveness was recorded after 72 hours and one week of application. After one week of the application, $2.00 \%$ mint concentration cause maximum mortality $(96.70 \%)$, followed by 1.50 (73.30\%), $1.00(46.70 \%)$ and $0.50 \%(40.00 \%)$ concentrations. No mortality of $T$. confusum individuals was recorded in the control. Thus, after one week, a significant difference $(\mathrm{F}=33.30, \mathrm{P}<$ 0.001) was observed in different mint concentrations to cause mortality among individual beetles of $T$. confusum

Table 1. Effect of different mint concentrations on mortality of $T$. confusum at different intervals under laboratory conditions.

\begin{tabular}{|c|c|c|c|c|c|}
\hline \multirow{2}{*}{ Treatments } & \multicolumn{3}{|c|}{ Population at different observation Intervals } & \multirow{2}{*}{ Mortality \% } \\
\cline { 2 - 6 } & Pre-treatment & $\mathbf{2 4}$ hours & $\mathbf{4 8}$ hours & One week & $40.00 \%$ \\
\hline $0.50 \%$ & 10 & $0.67 \pm 0.33 \mathrm{ab}$ & $1.00 \pm 0.58 \mathrm{bc}$ & $4.00 \pm 1.00 \mathrm{c}$ & $46.70 \%$ \\
\hline $1.00 \%$ & 10 & $1.33 \pm 0.33 \mathrm{ab}$ & $1.67 \pm 033 \mathrm{~b}$ & $4.67 \pm 0.33 \mathrm{c}$ & $73.30 \%$ \\
\hline $1.50 \%$ & 10 & $1.67 \pm 0.67 \mathrm{a}$ & $4.00 \pm 0.58 \mathrm{a}$ & $7.33 \pm 0.88 \mathrm{~b}$ & $96.70 \%$ \\
\hline $2.00 \%$ & 10 & $2.00 \pm 0.58 \mathrm{~b}$ & $4.67 \pm 0.67 \mathrm{a}$ & $9.67 \pm 0.33 \mathrm{a}$ & $0.00 \%$ \\
\hline
\end{tabular}

Effect of different mint concentrations on the population fluctuation of $T$. confusum: Results for the population fluctuation of $T$. confusum in wheat treated with various mint extracts are given in Table 2. A significant difference was recorded in the population of $T$. confusum in different mint extracts treated wheat after first month $(\mathrm{F}=18.5, \mathrm{P}$ $<0.0001)$, second month ( $\mathrm{F}=53.2, p<0.0000)$ and third month $(\mathrm{F}=46.5, \mathrm{P}<0.0000)$ of observations. After one month, the highest mean population was recorded in control (21.00 \pm 1.73 beetles), followed by $0.50 \%$ ( $15.00 \pm 1.53$ beetles), $1.00 \%$ ( $11.33 \pm 0.88$ beetles), $1.50 \%(8.67 \pm 1.45$ beetles) and $2.00 \%$ ( $6.00 \pm 11.00$ beetles). In the remaining two months of observations, steady growth was observed in the $2 \%, 1.5 \% 1 \%$, and $0.5 \%$ concentration; however, rapid growth was recorded in the control. Accordingly, at the end of month three, the highest population of $T$. confusum was recorded in control $(88.00 \pm 3.79$ beetles), whereas, the beetle 
population observed in $0.50 \%, 1.00 \%, 1.50 \%$, and $2 \%$ concentrations were $(71.33 \pm 1.45$ beetles $)$,
(63.00 \pm 3.46 beetles), $(53.67 \pm 2.91$ beetles) and

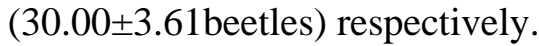

Table 2. Effect of different mint concentrations on the population fluctuation of $T$. confusum in wheat grains under laboratory conditions.

\begin{tabular}{|c|c|c|c|c|}
\hline Treatments & \multicolumn{4}{|c|}{ Population at different observation Intervals } \\
\cline { 2 - 5 } & Pre-treatment & $\mathbf{1}^{\text {st }}$ Month & $\mathbf{2}^{\text {nd }}$ Month & $\mathbf{3}^{\text {rd }}$ MONTH \\
\hline $0.05 \%$ & 20 & $15.00 \pm 1.53 \mathrm{~b}$ & $46.33 \pm 2.60 \mathrm{~b}$ & $71.33 \pm 1.45 \mathrm{~b}$ \\
\hline $1 \%$ & 20 & $11.33 \pm 0.88 \mathrm{bc}$ & $34.00 \pm 4.36 \mathrm{c}$ & $63.00 \pm 3.46 \mathrm{bc}$ \\
\hline $1.05 \%$ & 20 & $8.67 \pm 11.45 \mathrm{~cd}$ & $25.33 \pm 1.86 \mathrm{c}$ & $53.67 \pm 2.91 \mathrm{c}$ \\
\hline $2 \%$ & 20 & $6.00 \pm 11.00 \mathrm{~d}$ & $13.67 \pm 1.76 \mathrm{~d}$ & $30.00 \pm 3.61 \mathrm{~d}$ \\
\hline Control & 20 & $21.00 \pm 1.73 \mathrm{a}$ & $70.67 \pm 3.53 \mathrm{a}$ & $88.00 \pm 3.79 \mathrm{a}$ \\
\hline
\end{tabular}

The overall weight loss in wheat due to the feeding of $T$. confusum under the effect of different mint concentrations mixed with wheat is given in Table 3 . Results indicated that overall weight loss in various concentrations showed a highly significant difference $(\mathrm{F}=44.2, \mathrm{P}<0.0000)$ due to feeding of T. confusum. Accordingly, at the end of the experiment, the highest weight loss was observed in control (47.00 grams or $23.50 \%$ ), followed by
$0.50 \%$ (39.33 grams or $19.67 \%)$ and $1.50 \%(24.33$ grams or $12.17 \%$ ) concentrations. The lowest overall weight loss was observed in $2.00 \%$ mint concentration (11.33 grams or $5.67 \%$ ). Similar to overall weight loss, significantly $(\mathrm{F}=69.90, \mathrm{P}<$ 0.001 ) the lowest and highest grain weight loss was observed in $2.00 \%$ mint concentration (17.33 grams or $8.67 \%$ ) and control (54.00 grams or $27.00 \%$ ), respectively.

Table 3. Weight loss of wheat grains mixed with different mint concentrations by $T$. confusum under laboratory conditions.

\begin{tabular}{|c|c|c|c|c|c|}
\hline Treatments & $\begin{array}{l}\text { Initial weight } \\
\text { (grams) }\end{array}$ & $\begin{array}{l}\text { Final weight } \\
\text { (grams) }\end{array}$ & $\begin{array}{l}\text { Grain weight } \\
\text { (grams) }\end{array}$ & $\begin{array}{l}\text { Over all weight } \\
\text { loss (grams / \%) }\end{array}$ & $\begin{array}{l}\text { Grain weight loss } \\
\text { (grams / \%) }\end{array}$ \\
\hline $0.50 \%$ & 200 & $160.67 \pm 1.45 \mathrm{~d}$ & $152.67 \pm 0.88 \mathrm{~d}$ & $\begin{array}{l}39.33 \mathrm{~g} \\
(19.67 \%) \\
\end{array}$ & $\begin{array}{l}47.33 \mathrm{~g} \\
(23.67 \%) \\
\end{array}$ \\
\hline $1.00 \%$ & 200 & $167.67 \pm 1.45 c$ & $160.33 \pm 0.88 \mathrm{c}$ & $\begin{array}{l}32.33 \mathrm{~g} \\
(16.17 \%)\end{array}$ & $\begin{array}{l}39.67 \mathrm{~g} \\
(19.83 \%)\end{array}$ \\
\hline $1.50 \%$ & 200 & $175.67 \pm 1.45 b$ & $169.33 \pm 1.20 \mathrm{~b}$ & $\begin{array}{l}24.33 \mathrm{~g} \\
(12.17 \%) \\
\end{array}$ & $\begin{array}{l}30.67 \mathrm{~g} \\
(15.33 \%) \\
\end{array}$ \\
\hline $2.00 \%$ & 200 & $188.67 \pm 0.88 \mathrm{a}$ & $182.67 \pm 0.88 \mathrm{a}$ & $\begin{array}{l}11.33 \mathrm{~g} \\
(5.67 \%) \\
\end{array}$ & $\begin{array}{l}17.33 \mathrm{~g} \\
(8.67 \%) \\
\end{array}$ \\
\hline Control $(0 \%)$ & 200 & $153.00 \pm 3.79 \mathrm{e}$ & $146.00 \pm 2.52 \mathrm{e}$ & $\begin{array}{l}47.00 \mathrm{~g} \\
(23.50 \%)\end{array}$ & $\begin{array}{l}54.00 \mathrm{~g} \\
(27.00 \%)\end{array}$ \\
\hline
\end{tabular}

\section{Discussion}

Although, not much research has been carried out on the insecticidal properties of mint, but in different regions of the world, various locally available plants were evaluated against noxious insect pests for their detrimental effects. Among these studies, Khani and Rahdari (2012) proved that essential oil extracted from coriander seeds was found effective against adults of $T$. confusum and $C$. maculatus as significant mortality was recorded in 1 to 7-day-old adults of both the species. The mortality of pests increased with the rise in the concentration of the oils from 43 to 357 $\mu \mathrm{L} / \mathrm{L}$ air and exposure timing from 3 to 24 hours. (Sener et al., 2009) also described the insecticidal properties of essential oils obtained from $R$. officinalis, $S$. officinalis, $O$. syriacum, and $T$. vulgaris against $T$. confusum in stored wheat. The $\gamma$-terpinene, $\beta$-thujone, 1,8 -cineole, and p-cymene, respectively were the main constituents of the plant materials used in the study. Different concentrations i.e., $2,4,8,16$, and $32 \mu \mathrm{L} / 100 \mathrm{~mL}$ jar were applied on the filler paper for various plant essential oils. The results obtained indicated that 
with an increase in the concentrations of the oils, a rise in the mortality of the targeted beetles was recorded. Among the constituents of the four plants, 1,8-cineole obtained from rosemary and common sage caused the highest mortality, followed by $\beta$-thujone from common sage and $\mathrm{p}$ cymene from thyme. Another study also highlighted the potential of the powders and the extracts of hexane and methanol of seeds and leaves of A. indica, B. aeggptiaca, and $O$. basilicum against Trogoderma granarium and $T$. castaneum. All the extracts were applied against $1^{\text {st }}$ to $4^{\text {th }}$ larval instars along with adults both species at $0,1,2,4$, and 5-gram doses of the various plant parts extracts and the insecticide primiphos (Actellic 50\% EC). After 14 days of exposure, $100 \%$ mortality of adult $T$. granarium was recorded with the application of all the concentrations of B. aeggptiaca kernels. However, after 14 days of exposure, comparatively lower mortalities were observed in the $1^{\text {st }}$ and $4^{\text {th }}$ larval instars and adults of $T$. castaneum when $B$. aeggptiaca was applied at the above concentrations. Laloub kernels hexane extracts showed $100 \%$ mortality of the $1^{\text {st }}$ larval instar and adult stage of $T$. granarium and $T$. castaneum after 14 days at all concentrations, while the $4^{\text {th }}$ larval stage showed few percentage mortalities (Mohamed, 2015). (Hanif et al.,2016) determined the repellency and mortality of $T$. castaneum due to the application of tobacco, bitter apple, and neem using the filter papers. The concentration of three botanicals used in the study aswas $5.0 \%, 10 \%$, $15 \%$, whereas, observations were recorded after 24 , 48, 1 week, one, two, and three months of the application. All the tested plants showed good results to cause repellency among the individuals of T. castaneum with repellency of $26.56 \%, 25.67 \%$, and $23.89 \%$ recorded for bitter apple, neem, and tobacco, respectively. The maximum mortality results were obtained with the use of tobacco at $10 \%$ concentration that caused $86 \%$ mortality after 48 hours of application. Neem extracts exhibited more repellency effects than to cause mortality. (Khan et al., 2016) also studied the growthinhibiting properties of botanicals i.e., Verbena tenuisecta, Parthenium hysterophorus, Calotropis procera, and $A$. indica as growth inhibitors of $T$. castaneum. Various extracts were prepared using either ethanol or acetone. Extracts of $V$. tenuisecta at a concentration of $500 \mathrm{ppm}$ was proved effective in reducing the egg-laying of beetles as minimum fecundity (61.00) was recorded in it, followed by $A$. indica (77.50 eggs) at $1000 \mathrm{ppm}$ concentration. The maximum mean oviposition (139.67) was recorded in wheat flour treated with $P$. hysterophorus at 500 concentrations, followed by the same plant extracts (144.67 eggs) when applied at $250 \mathrm{ppm}$ concentration. P. hysterophorus was also found the most efficient inthe fertility of the $T$. castaneum followed by $V$. tenuisecta, both applied at $500 \mathrm{ppm}$. However, C. procera at $1000 \mathrm{ppm}$ concentration caused the maximum larval inhibition, but not significantly different from remaining treatments including control. Maximum pupal inhibition was recorded in flour treated with $V$. tenuisecta extracts. It was also observed that the fecundity of $T$. castaneum was more affected by the acetone extracts of various plants, whereas, other parameters were more influenced by ethanol extracts.

\section{Conclusion}

All the mint concentrations exhibited the potential to elicit mortality and influence the population of $T$. confusum. While $2.00 \%$ of mint concentration caused the highest mortality and support less population development of $T$. confusum. The lowest mortality and maximum population growth were recorded in $0.50 \%$ mint concentration. Overall, the maximum and minimum weight loss was recorded in control and $2.00 \%$ mint concentration.

\section{References}

Alanko, K., T. Tuomi, M. Vanhanen, M. P. Backas, L. Kanerva, K. Havu, K. Saarinen, and D. P. Bruynzeel. (2000). Occupational IgE-mediated allergy to Tribolium confusum (Confused flour beetle). Allergy, 55: 879-882.

Athanassiou, C. G., N. G. Kavallieratos and J. F. Campbell. (2016). Capture of Tribolium castaneum and Tribolium confusum (Coleoptera: Tenebrionidae) in floor traps: the effect of previous captures. Journal of Economic Entomology, 109 (1): 461-466.

Atiyah, R. M., C. A. Edwards, J. D. Metzger, S. Lee and N. O. Arancon. (2002). The influence of humic acids derived from earthworm processed organic wastes on plant growth. Bioresource Technology, 84 (1): 7-14. 
GoP. (2018). Area, production and yield of wheat, 201718. Pakistan Bureau of Statistics, Government of Pakistan.

Hajlaoui, H., M. Snoussi, H. B. Jannet, Z. Mighri and A. Bakhrouf. (2008). Comparison of chemical composition and antimicrobial activities of Mentha longifolia (L). ssp. Longifoli essential oil from two Tunisian localities (Gabes and Sidi Bouzid). Annals of Microbiology, 58 (3): 513.

Hanif, M. S., M. Hasan, M. Sagheer, H. M. Atif, R. Malik and M. Waqas. (2016). Insecticidal activity of different botanicals (bitterapple, neem and tobacco) towards Tribolium castaneum (Coleoptera: Tenebrionidae). Journal of Global Innovation, Agriculture and Social Sciences, 4 (4): 197-203.

Degri, M. M., \& Zainab, J. A. (2013). A study of insect pest infestations on stored fruits and vegetables in the northeastern Nigeria. Int J Sci Nat, 4(4), 646-650.

Haq, T., N. F. Usmani and T. Abbas. (2005). Screening of plant leaves as grain protectants against Tribolium castaneum during storage. Pakistan Journal of Botany, 37 (1): 149-153.

Isman, M. B. (2000). Plant essential oils for pest and disease management. Crop Protection, 19: 603-608.

Isman, M. B. (2006). Botanical insecticides, deterrents, and repellents in modern agriculture and an increasingly regulated world. Annual Review of Entomology, 5 (1): 45-66.

Khan, I., N. Qureshi, S. A. Khan, A. Ali, M. Ahmad and K. Junaid. (2016). Efficacy of several plant extracts as growth inhibitors against red flour beetle, Tribolium castaneum (Herbst) (Coleoptera: Tenebrionidae). Acta Zoologica Bulgarica, 68 (3): 443-450.

Khani, A. and J. Rahdari. (2012). Insecticide activity of essential oils of Mentha longifolia, Pulicaria gnaphalodes and Achillea wilhelmsii against two stored product pests, the flour beetle, Tribolium castaneum, and the cowpea weevil, Callosobruchus maculatus. Journal of Insect Science, 12 (1): 213220.

Lange, B. M. and R. Croteau. (1999). Isoprenoid biosynthesis via a mevalonate-independent pathway in plants cloning and heterologous expression of 1deoxy-D-xylulose-5-phosphate reductoisomerase from peppermint. Archives of Biochemistry and Biophysics, 365 (1): 170-174.

Lee, B. H., S. E. Lee, P. C. Annis, S. J. Pratt, B. S. Park and F Tumaalii. (2002). Fumigant toxicity of essential oils and monoterpenes against the red flour beetle, Tribolium castaneum Herbst. Journal of Asia-Pacific Entomology, 5 (2): 237-240.

Mackowiak, C. L., P. P. Grossi and B. G. Bugbei. (2001). Beneficial effect of humic acid on micronutrients availability of wheat. Soil Science Society of America Journal, 65 (6):1744- 1750.
Mohamed, N. M. A. (2015). Efficacy of selected plants extracts on the control of khapra beetle Trogoderma granarium Everts (Coleoptera: Dermistidae) and red flour beetle Tribolium castaneum (Herbst) (Coleoptera: Tenebri) (Doctoral Dissertation, $\mathrm{UOFK}$ ).

Oyedeji, A. O. and A. J. Afolayan. (2006). Chemical composition and antibacterial activity of the essential oil isolated from South African Mentha longifolia (L.) Journal of Essential Oil Research, 18: 57-60.

Rahman, M. M., W. Islam and K. N. Ahmed. (2009). Functional response of the predator Xylocoris flavipes to three stored product insect pests. International Journal of Agriculture Biology, 11: 316320.

Rahmat, U. K., A. Rashid, M. S. Khan and E. Ozturk. (2010). Impact of humic acid and chemical fertilizer application on growth and grain yield of rain fed wheat (Triticum aestivum, L.). Pakistan Journal Agriculture Research, 23 (4): 113-121.

Rajendran, S. and V. Sriranjini. (2008). Plant products as fumigant for stored-product insect control. Journal of Stored Product Research, 44: 12 - 135.

Sener, O., M. Arslan, N. Demirel and I. Uremis. (2009). Insecticidal effects of some essential oils against the confused flour beetle (Tribolium confusum du Val) (Coleoptera: Tenebrinoidea) in stored wheat. Asian Journal of Chemistry, 21 (5): 3995-4000.

Shaaya, E., M. Kostjukovski, J. Eilberg and C. Sukprakarn. (1997). Plant oils as fumigants and contact insecticides for the control of stored-product insects. Journal of Stored Products Research, 33 (1): 7-15.

Trematerra, P., A. Sciarretta and E. Tamasi (2000). Behavioural responses of Oryzaephilus surinamensis, Tribolium castaneum and Tribolium confusum to naturally and artificially damaged durum wheat kernels. Entomologia Experimentalis et Applicata, 94: 195-200. 